Running head: COVID-19, EXISTENTIAL THREAT, AND ANXIOUS AROUSAL 1

\title{
Framing COVID-19 as an Existential Threat Predicts Anxious Arousal and Prejudice towards Chinese People
}

\author{
Nassim Tabri \\ Department of Psychology, Carleton University \\ Samantha J. Hollingshead \\ Department of Psychology, Carleton University \\ Michael J. A. Wohl \\ Department of Psychology, Carleton University
}

This manuscript has not been peer-reviewed. It is a working draft and may undergo revision and refinement as we receive feedback from the scientific community. The research was supported by a Social Sciences and Humanities Research Council of Canada research grant to Tabri [4302019-00941] and to Wohl [435-2012-1135]. Correspondence concerning this article should be directed to Nassim Tabri, nassim.tabri@ carleton.ca 


\begin{abstract}
We tested the hypothesis that perceived existential threat stemming from COVID-19 elicits anxious arousal, which can manifest in prejudice toward the perceived source of the threat (Chinese people). Americans $(n=474)$ were randomly assigned to an experimental condition in which COVID-19 was framed as an existential threat to the United States or a non-existential threat control condition. They then completed self-report measures of anxious arousal as well as subtle and blatant prejudice towards Chinese people. As expected, participants in the threat (vs. control) condition reported greater anxious arousal which, in turn, predicted greater subtle and blatant prejudice. Threat (vs. control) condition also indirectly predicted greater subtle and blatant prejudice via greater anxious arousal. Results suggest that COVID-19 existential threat may diminish social capital, which would further degrade people's health and well-being.
\end{abstract}

Keywords: Anxiety; collective angst; COVID-19; prejudice; threat; 


\section{Framing COVID-19 as an Existential Threat Predicts Anxious Arousal and Prejudice towards Chinese People}

Like previous global pandemics (e.g., H1N1, SARS), the novel coronavirus (COVID-19) pandemic has disrupted human existence. At the time of writing this paper (April 14, 2020), COVID-19 has infected over 1,988,890 people and claimed 125,729 lives world-wide (Worldometer, 2020) and continues to threaten the health and well-being of humanity. It has also created a global economic crisis, which will likely culminate in a global recession. On an individual economic level, people are losing their jobs, losing their savings (if any were had to begin with), and thus finding it increasingly difficult to pay their bills. Meanwhile, public health officials are imploring people to engage in social distancing to "flatten the curve" (i.e., reduce the rate of COVID-19 cases over time), resulting in the physical separation of people who could otherwise provide social support whilst they try to contend with the fallout from this highly contagious virus — one that can be spread quickly by those who are visibly ill, but also by people who are asymptomatic. With a vaccine many months if not a year and a half away, and the outbreak growing exponentially, it is natural for many people to feel they are under existential threat. They are not wrong to feel this way. The greatest death toll humanity has experienced stems from infectious diseases; the Black Death was responsible for the loss of approximately $25 \%$ of the European population (Scott \& Duncan, 2001).

Of course, all living organisms eventually die. Distressing for many people is that they have only a limited amount of control over how it will unfold, and when it will end. Thinking about such existential threat creates anxiety (see Barlow, 1988; Becker, 1973/2007; Rank, 1909/1914; Sartre, 1956), which may be heightened during the spread of a virulent disease or pandemic. For example, Wheaton and colleagues (2012) found that fears of contamination 
during the H1N1 influenza (i.e., swine-flu) pandemic heightened HIN1-related anxiety.

However, anxiety can take several different forms. For instance, people may experience acute symptoms of anxiety. Among other symptoms, people experience difficulty breathing, heart racing, and lightheadedness. They may also experience concern about their own survival and corresponding feelings of nervousness and fear (e.g., fear of dying). Moreover, they may come to feel concerned about the possible demise of a cherished group to which they belong (e.g., a fitness studio club), the future vitality of their culture or nation (e.g., Italy) or even humanity. Such group-based anxiety, or collective angst (Tabri et al., 2018; Wohl et al., 2012), can activate similar neural processes that underlie anxious states (Jonas et al., 2014). Although anxiety (about COVID-19) may take different forms, they reflect a common underlying process of anxious arousal. Indeed, anxiety is a chameleon-like force that presents itself in a variety of ways, but regardless of source creates a generalized or unspecified sense of disequilibrium - a feeling of unease, tension, worry, or apprehension about what may transpire (see Baumeister, Smart, \& Boden, 1996; Gray, 1982; Horwitz, 2013).

What are the consequences of anxious arousal stemming from COVID-19 being perceived to be an existential threat? The answer resides in the emotional goal of anxiety, which is to alert the organism of impending danger and engage in self-protective action (Barlow, 1988; Becker, 1973/2007; Gray, 1982; Wohl, Squires, Caouette, 2012). From a public health perspective, this emotional goal of anxiety may help explain how people respond during a pandemic_- people take action they deem capable of eliminating the existential threat. This may manifest in prejudicial attitudes toward a perceived source of the existential threat (Schaller \& Neuberg, 2008; Tabri et al., 2018; Wohl et al., 2012). Indeed, affective states, such as anxiety, produce simplified information processing, which has implications for the use of stereotypic, 
rather than individuating, information in social perception (Bodenhausen, 1993; Stephan \& Stephan, 2013). As evidence of this, Kessler and colleagues (2010) found that, among a sample of German youth, higher intergroup anxiety was predictive of higher levels of blatant prejudice toward immigrants. In the case of COVID-19, this is particularly relevant given President Trump's framing of the virus as the "Chinese virus"- a situation which may heighten prejudice toward Chinese people. Importantly, previous research that has examined the association between existential threat, anxiety and prejudice has been correlational in nature - the causal association between the variables is yet to be established.

In the current research, we tested the hypothesis that perceiving COVID-19 as an existential threat promotes subtle and blatant prejudice towards Chinese people via greater anxious arousal, as reflected by self-reported levels of acute anxiety symptoms, feelings of state anxiety, and collective angst. We tested this hypothesis in a community sample of Americans on February 27, 2020, prior to the COVID-19 outbreak being declared a national emergency in the United States and when the epicenters of the COVID-19 outbreak were in China and Europe (i.e., only a few presumptive cases were reported in the United States).

\section{Method}

All research materials, statistical input and output files, and the analyzed data reported herein can be accessed via the Open Science Framework (OSF):

https://osf.io/82kbv/?view_only=1000b7e1ce554d0586b8353384ac6a58

\section{Participants}

A total of 692 American citizens residing in the U.S. were recruited via Amazon's Mechanical Turk (MTurk). They responded to a recruitment notice for a survey titled “American's Opinion about China” and received US \$0.75 for their time. 
Data from 218 participants were excluded because they did not complete any of the questionnaires $(n=78)$, failed a comprehension check $(n=66)$, did not complete one or more of

the post-manipulation questionnaires $(n=37)$, were of Asian background $(n=31)$, had excessive missing data $(n=4)$, or did not consent to the use of their data $(n=2)$. Thus, the final sample consisted of 474 participants ( 250 men and 224 women) who ranged in age from 19 to 76 $(M=37.32, S D=11.33)$.

\section{Procedure and materials}

Upon granting consent, participants completed demographic items (e.g., age and sex) and questionnaires included for exploration that were not examined in the current research.

Participants were then randomly assigned to read one of two news articles about the threat of COVID-19 to the United States. In the high threat condition (see Figure 1a), they read that Chinese travel to the United States would increase and bring the coronavirus with it, which would severely harm the health and well-being of Americans. Additionally, they were told the United States would be unable to contain the coronavirus from spreading throughout the United States. In the low threat condition (see Figure 1b), participants read that Chinese travel to the United States was on the decline, which would slow the spread of the coronavirus to Americans. They were also told that the United States would be able to contain the coronavirus, and thus it would cause little or no damage to the health and well-being of Americans.

Figure 1a. Threat condition of COVID-19 threat manipulation 


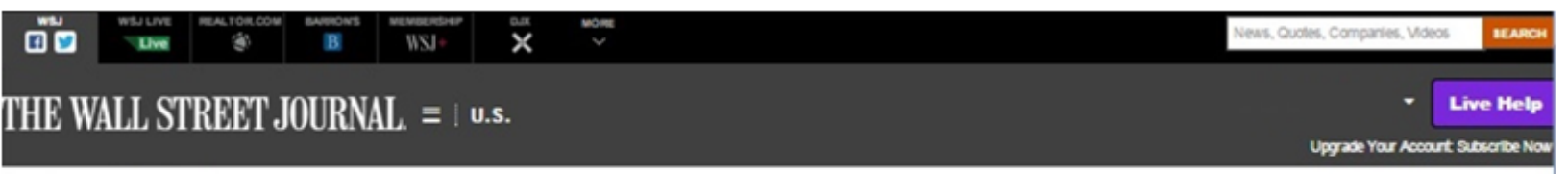

U.S. NEWs

Coronavirus, America and you: Things Americans Should Know

Brookings Institute Press Release

BY JULIANE E. BARNES

WASHINGTON - A recent report by the Brookings Institute confirmed that there is a high probability that Chinese travel to the U.S. will exceed last year's

-.. rate, and this increase will likely continue for the foreseeable future. The report also stated that the influx of Chinese visitors to the U.S. will inevitably bring the coronavirus - a respiratory illness which travels through the air in tiny droplets that are produced when an infected individual talks, coughs or sneezes - to America. Alex Azar the U.S. Secretary of Health and Human Services, said that an outbreak of the virus would severely harm the American people and cause great damage to the health and well-being of our population.

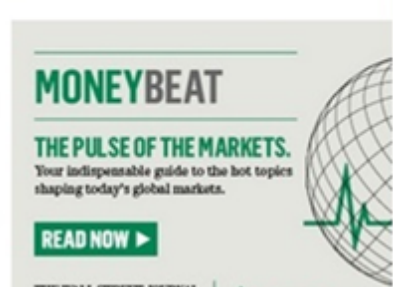

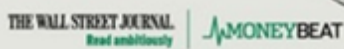

The report concluded with an ominous warning that efforts to control the coronavirus coming from Chinese travellers have been unsuccessful because America is unable to completely close its skies and borders.

Figure 1b. Control condition of COVID-19 threat manipulation

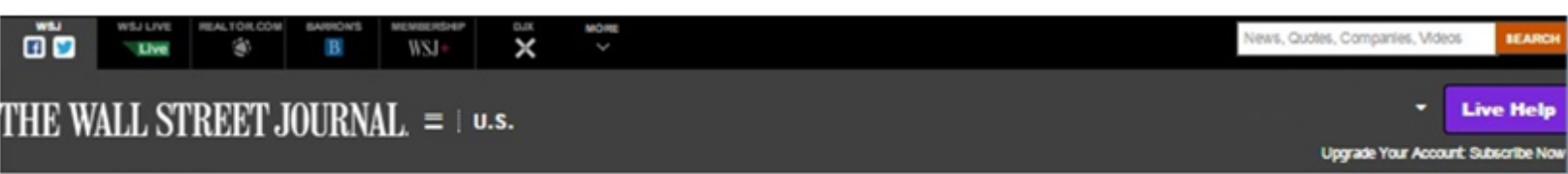

U.S. NEWS

Coronavirus, America and you: Things Americans Should Know

Brookings Institute Press Release

BY JULIANE E. BARNES

WASHINGTON - A recent report by the Brookings Institute confirmed that there is a low probability that Chinese travel to the U.S. will exceed last year's

‥ rate, and this decrease will likely continue for the foreseeable future. The report also stated that the declining influx of Chinese visitors to the U.S. will curtail the coronavirus - a respiratory illness which travels through the air in tiny droplets that are produced when an infected individual talks, coughs or sneezes - from spreading in America. Alex Azar, the U.S. Secretary of Health and Human Services, said that the virus in the U.S. can be quickly contained so

\section{MONEYBEAT}

THE PULSE OF THE MARKETS.

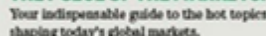
READNOW -

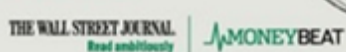
will not harm the American people, and cause little or no damage to the health and well-being of our population.

The report concluded with a positive outlook that efforts to control the coronavirus coming from Chinese travellers have been successful because America is able to adequately control its skies and borders. 
Thereafter, participants completed a comprehension check item ("in a few words, please tell us what the article you just read was about") followed by three manipulation check items that assessed harm probability ("how likely you think that the prevalence of the Coronavirus in the US will increase in the near future"), harm severity ("how harmful you think that the Coronavirus will be for the United States"), and collective efficacy ("how confident you are in the ability of the United States to control the Coronavirus in the United States"). Responses to these items where anchored at 0 (not at all) and 9 (highly likely). They then completed several questionnaires of which the following were examined in the current research:

Acute anxiety symptoms. The Beck Anxiety Inventory (BAI; Beck et al., 1988) was used to assesses the extent to which people experience 21 symptoms of acute anxiety in the past month (e.g., "numbness or tingling," "Heart pounding/racing," and "fear of dying"). We modified the instructions of the BAI so that participants responses reflected anxiety symptoms they were currently experiencing as a result of reading the content of the article. Responses were anchored at 1 (not at all) and 7 (extremely) and averaged such that higher scores indicated greater acute anxiety $(\alpha=.99)$.

State anxiety. Participants completed the short-form of the State Scale from the Spielberger State-Trait Anxiety Inventory (Marteau \& Bekker, 1992). They were instructed to report the extent to which they felt clam (reverse-coded), tense, upset, relaxed (reverse-coded), content (reverse-coded), and worried as a result of reading the content of the article. Responses were anchored at 1 (not at all) and 7 (extremely) and averaged such that higher scores indicated greater state anxiety $(\alpha=.65)$.

Collective angst. Participants completed a five-item scale that measured their level of collective angst for America (adapted from Wohl, \& Branscombe, 2009; e.g., "I feel anxious 
about the future of the United States"). Responses were anchored at 1 (strongly disagree) and 7 (strongly agree) and averaged such that higher scores reflected greater collective angst $(\alpha=.77)$.

Prejudice. Participants completed a 10-item scale that measured their subtle (e.g., "Chinese people are very different from Americans in their hygienic habits") and blatant (e.g., "Chinese people are a less abled race, which is why they are not as well off as Americans") prejudice towards Chinese people (adapted from Pettigrew \& Meertens, 1995; Ungaretti et al., 2018). Responses were anchored at 1 (strongly disagree) and 7 (strongly agree) and averaged such that higher scores reflected greater subtle $(\alpha=.79)$ and blatant prejudice $(\alpha=.92)$.

\section{Statistical analysis}

A mediation model was estimated in which condition ( $0=$ low threat, $1=$ high threat $)$ was the independent variable, anxious arousal was the mediator variable, and subtle and blatant prejudice was the dependent variables (see Figure 2). The mediator was calculated as an average score of the standardized ( $z$-score) versions of the BAI, state anxiety, and collective angst average scores. Mplus version 8.2. (Muthén \& Muthén, 1998-2017) was used to conduct the analysis with maximum likelihood estimation. The statistical significance of the indirect effects were evaluated using the $95 \%$ bias-corrected bootstrapped confidence interval based on 5000 resamples.

\section{Statistical power}

In the interest of openness and transparency, we note that the data analyzed in the current research were initially collected for another research project focused on a related topic (existential threat, collective angst, and rumination on threat; see pre-registration on OSF: https://osf.io/u9wk8). However, given the rapidly evolving COVID-19 situation, we decided to test a novel hypothesis (which we tested in the current paper). In haste to examine this new 
hypothesis and contribute to the conversation on the social psychology of COVID-19, we negated to pre-register the new hypothesis or conduct an a priori power analysis before analyzing the data.

We did conduct a Monte Carlo post-hoc power analysis in which the results were simulated 10,000 times to determine power for the direct and indirect effects with the reported sample size. The findings indicated that the key direct effects (paths "a" and " $b$ " in the mediation model) and the indirect effects were powered between .69 and 1.00. We also used Schoemann, Boulton, \& Short's (2017) Monte Carlo Power Analysis for Indirect Effects tool to determine the minimum sample size to detect the indirect effects with $80 \%$ power and alpha of .05 . The results indicated that a minimum of 650 participants would be needed for the indirect effect involving subtle prejudice and 200 participants would be needed for the indirect effect involving blatant prejudice. As such, power to predict subtle prejudice was low, whereas power to predict blatant prejudice was high.

\section{Results}

\section{Manipulation check}

Participants in the threat condition $(n=241)$ reported a higher likelihood that the prevalence of COVID-19 would increase in the near future $(M=7.88, S D=2.49)$ than those in the control condition $(n=231 ; M=6.95, S D=2.94), t(470)=3.70, p<.001, d=.34$. Those in the threat condition also reported greater harm to the US from COVID-19 $(M=6.78, S D=2.52)$ than those in the control condition $(M=6.19, S D=2.83), t(469)=2.42, p=.02, d=.22$. However, participants in the threat $(M=6.96, S D=2.55)$ and control $(\mathrm{M}=7.30, \mathrm{SD}=2.62)$ conditions did not differ in terms of their confidence in the ability of the US to control the spread of COVID-19 in the US, $t(470)=1.43, p=.15$. Thus, although perceived collective efficacy of 
to control the spread of COVID-19 in the US was moderate in both conditions, the threat manipulation was successful in terms of increasing the perceived likelihood of COVID-19 in the US and that the presence of COVID-19 would severely harm the US population.

\section{Mediation model}

Descriptive statistics and correlations between all measured variables are in Table 1 and results of the mediation model are summarized in Figure 2. Americans who read about COVID19 being an existential threat reported greater anxious arousal than did those who read about COVID-19 not becoming a domestic issue $(b=.33, S E=.07, p<.001,95 \%$ CI [.20, .46]). This greater anxious arousal, in turn, predicted more subtle $(b=.20, S E=.08, p=.015,95 \%$ CI [.04, $.36])$ and blatant $(b=.93, S E=.12, p<.001,95 \% \mathrm{CI}[.70,1.17])$ prejudice toward Chinese people. Moreover, the indirect effect of the threat manipulation on subtle prejudice towards Chinese people via greater anxious arousal was statistically significant, indirect effect $=.07,95 \%$ CI $[.02, .13]$. Likewise, the indirect effect of the threat manipulation on blatant prejudice towards Chinese people via greater anxious arousal was statistically significant, indirect effect $=.31,95 \%$ CI $[.18, .46]$. The model explained $5 \%$ of the variance in anxious arousal, $1 \%$ of the variance in subtle prejudice, and $12 \%$ of the variance in blatant prejudice. Thus, in line with our hypothesis,

Table 1. Descriptive statistics and correlations between all measured variables.

\begin{tabular}{|c|c|c|c|c|c|c|c|c|}
\hline Variable & $M(S D)$ & 1 & 2 & 3 & 4 & 5 & 6 & 7 \\
\hline 1. Condition & $0.51(0.50)$ & - & & & & & & \\
\hline 2. Acute symptoms of anxiety & $2.16(1.69)$ & .06 & - & & & & & \\
\hline 3. State anxiety & $3.81(1.19)$ & $.25 * *$ & $.17 * *$ & - & & & & \\
\hline 4. Collective angst & $3.42(1.14)$ & $.19 * *$ & $.20 * *$ & $.50 * *$ & - & & & \\
\hline 5. Anxious arousal & $0.00(0.72)$ & $.23 * *$ & $.63 * *$ & $.76 * *$ & $.78 * *$ & - & & \\
\hline 6. Subtle prejudice & $5.66(1.25)$ & -.02 & $.31 * *$ & -.04 & -.04 & $.10 *$ & - & \\
\hline 7. Blatant prejudice & $3.79(1.92)$ & .03 & $.73 * *$ & -.03 & .04 & $.34 * *$ & $.50 * *$ & - \\
\hline
\end{tabular}

Note. Condition is coded $0=$ control and $1=$ threat. Anxious arousal was computed as the mean of $z$ scored versions of BAI, state anxiety, and collective angst.

$* p<.05 ; * * p<.01$.

$\mathrm{N}=474$. 
Americans who perceived COVID-19 as an existential threat reported more prejudice towards Chinese people through increased anxious arousal.

Figure 2. Effect of COVID-19 threat manipulation on prejudice towards Chinese people through its effect on anxious arousal. Note. Regression coefficients are unstandardized.

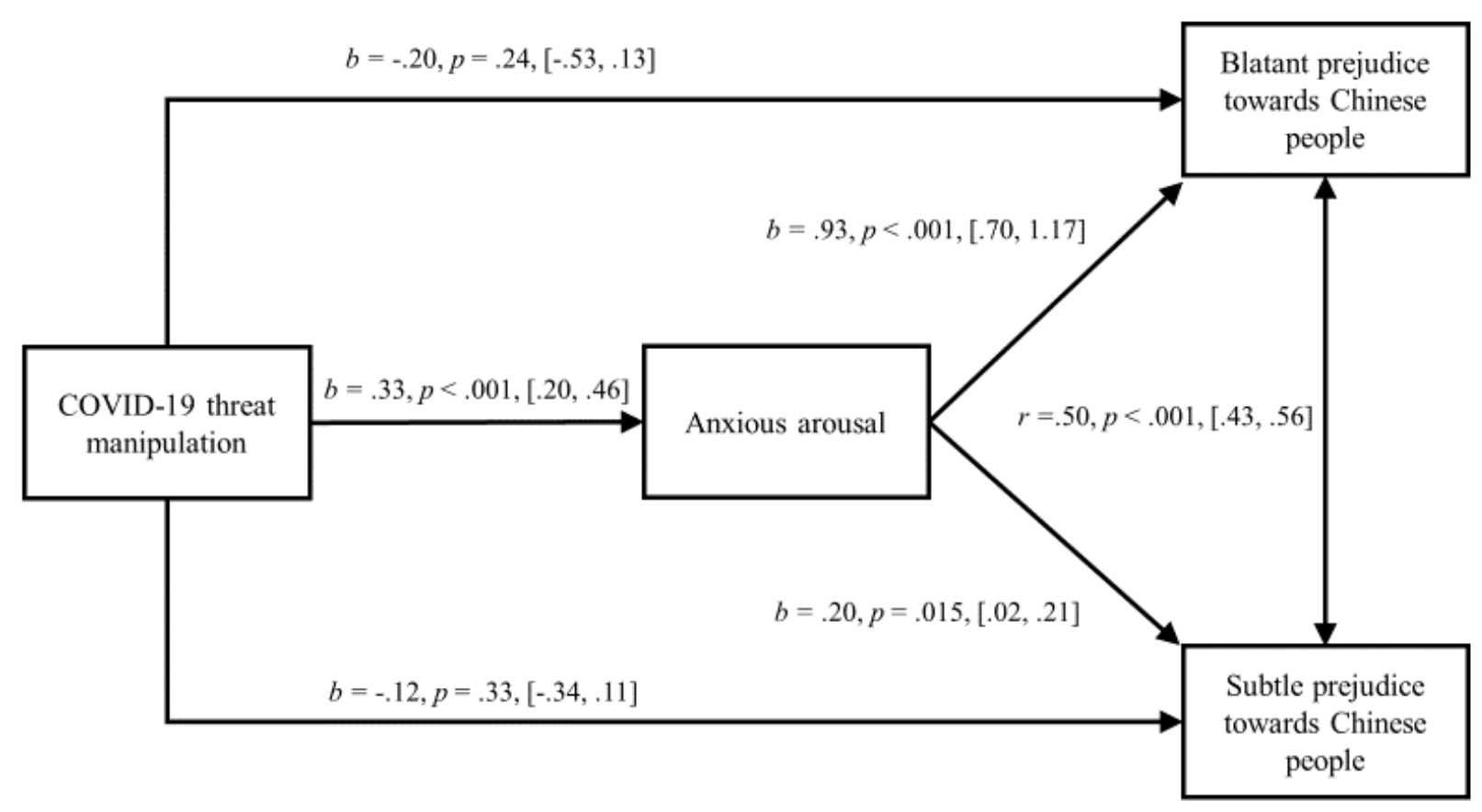

\section{Discussion}

Results reported herein are consistent with prior research that found perceived threat of a viral illness pandemic to be positively associated with worry and feelings of anxiety (e.g., Bults et al., 2011; Marshall et al., 2012; Wheaton et al., 2012). However, the extant research has been correlational in nature, thus undermining any causal inferences. In the current research, we showed that framing COVID-19 as an existential threat elicited anxious arousal expressed through acute anxiety symptoms, feelings of state anxiety, and collective angst. Thus, when 
COVID-19 is perceived as an existential threat it can place people at risk for developing distress and possibly anxiety disorders. The reason is that one of the three pathways to fear and anxiety disorders involves the transmission of information about threats to survival (Rachman, 1977). These findings are in line with research showing that greater exposure to media content about terrorist threat (Bodas, Siman-Tov, Kreitler, et al., 2015) or a virus outbreak (Thompson et al., 2017)) is associated with greater distress and elevated symptoms of acute anxiety. Of note, some symptoms of acute anxiety mimic many of the symptoms of COVID-19 (e.g., difficulty breathing).

An important direction for future research would be a longitudinal assessment of how COVID-19 related existential anxiety ebbs and flows over time and whether existential anxiety has prognostic importance for understanding the onset and maintenance of anxiety and stressrelated disorders. If existential anxiety is sustained, it may have a host of psychological, physiological, and behavioral ramification that could be witnessed on a global scale for years to come. In other words, a mental health pandemic may follow this physical health pandemic.

Anxious arousal also has social consequences. It leads to attitudes and action tendencies that are deemed capable of reducing or eliminating the existential threat (see Barlow, 1988; Becker, 1973/2007; Wohl et al., 2012). In the current research, we showed one outcome of COVID-19 related anxious arousal is blatant prejudice against Chinese people. This may have both short- and long-term negative consequences for social capital (i.e., the networks of relationships among people who live and work in a particular society; Putnam, 2000), which can further degrade people's health and well-being (Elgar et al., 2011). One way to help mitigate the negative consequences of COVID-19 based prejudice is to disseminate information to the general public about how and why people should feel less personally vulnerable to infection 
should they come into contact with Chinese people or their compatriots of Asian descent (Wohl et al., 2012).

At the time the research was conducted (February 27 2020), the epicenters of the COVID-19 outbreak were in China and Europe and so there were few government initiatives to promote hygiene practices, social distancing, and testing to help "flatten the curve" in the US. At the time of submission to Social Psychological and Personality Science, the epicenter of the COVID-19 outbreak has shifted to the US and the US has been slow to implement strategies to "flatten the curve" (e.g., closing schools and non-essential businesses). We only tested a negative outcome of anxious arousal (i.e., prejudice). However, anxious arousal stemming from COVID19 threat may also motivate people to engage in constructive action that helps "flatten the curve". People may start washing their hands with soap and water, engage in social distancing, and aid community members at the greatest risk (e.g., the elderly, people with immunodeficiencies). Likewise, anxious arousal stemming from perceiving COVID-19 as an existential threat may help explain panic purchasing and stockpiling of products (e.g., toilet paper, medicine) that may result in shortages for those in need of those products. It may also result in unnecessary strain on the medical system as these individuals request tests for COVID-19 and possibly expose themselves to the virus by leaving their homes to go to medical facilities for the test. To be clear, we are not implying that people who feel existential threat due to the COVID-19 threat are negative for the virus (i.e., their symptoms are merely a manifestation of the anxiety they are experiencing). Instead, the results of the current research provide a possible explanation for why many people are getting tested unnecessarily (Broffman, 2020). We call on researchers to examine how to best help people experiencing anxiety and distress due to the COVID-19 threat to help ease the burden on the world's health care systems. 
How people react to COVID-19 may depend on whether they feel capable of dealing with the threat - if people feel they have efficacy to minimize the risks of infection, they are likely to take socially constructive action (see Witte \& Allen, 2000). In this light, to help mitigate the risk of distress and anxiety disorders among the general public (who are for the most part in lockdown during the COVID-19 crisis), it would behoove governments and broadcasters (e.g., mass media) to share information on ways to help people cope more effectively with the distress stemming from the threat of COVID-19 in ways that increase self-efficacy. This information can include how to structure daily activities so that people can better meet their health needs (e.g., planned exercise sessions and adequate sleep), the needs of their family (e.g., schooling children, caring for elderly family members), and work-related needs. Other information can include access to freely available virtual or telephone resources that support mental health, such as online counseling and call centers to help with distress.

\section{Conclusion}

The current research is the first to demonstrate that experimentally induced COVID-19 existential threat causally evokes anxious arousal, which in turn was positively correlated with subtle and blatant prejudice towards the perceived source of the threat (i.e., Chinese people). Results also indicated that experimentally induced COVID-19 existential threat indirectly increased prejudice via greater anxious arousal. Together, the findings shed light on how the COVID-19 existential threat may degrade mental health and societal well-being. 


\section{References}

Barlow, D. H. (1988). Anxiety and its Disorders: The Nature and Treatment of Anxiety Disorder. Guilford Press.

Baumeister, R. F., Smart, L., \& Boden, J. M. (1996). Relation of threatened egotism to violence and aggression: The dark side of high self-esteem. Psychological Review, 103, 5-33.

Beck, A. T., Epstein, N., Brown, G., \& Steer, R. A. (1956). An inventory for measuring clinical anxiety: psychometric properties. Journal of Consulting and Clinical Psychology, 56, 893-897.

Becker, E. (1973/2007). The Denial of Death. The Free Press.Bodas, M., Siman-Tov, M., Kreitler, S., \& Peleg, K. (2015). Perception of the threat of war in Israel - implications for future preparedness planning. Israel Journal of Health Policy Research, 4, 35. https://doi.org/10.1186/s13584-015-0026-7

Bodas, M., Siman-Tov, M., Peleg, K., \& Solomon, Z. (2015). Anxiety-inducing media: the effect of constant news broadcasting on the well-being of Israeli television viewers. Interpersonal and Biological Processes, 78, 265-276. https://doi.org/10.1080/00332747.2015.1069658

Bodenhausen, G. V. (1993). Emotions, arousal, and stereotypic judgments: A heuristic model of affect and stereotyping. In Affect, Cognition and Stereotyping (pp. 13-37). Academic Press.

Broffman, L. (2020, March 19). Telemedicine can blunt the cost of unnecessary emergency visits for Covid-19. Stat. https://www.statnews.com/2020/03/19/telemedicine-blunt-costunnecessary-covid-19-visits/ 
Bults, M., Beaujean, D. J., de Zwart, O., Kok, G., van Empelen, P., can Steenbergen, J. E. Richardus, J. H., \& Voeten, H. A. (2011). Perceived risk, anxiety, and behavioural responses of the general public during the early phase of the Influenza A (H1N1) pandemic in the Netherlands: results of three consecutive online surveys. BMC Public Health, 11.

Elgar, F., Davis, C., Wohl, M., Trites, S., Zelenski, J., \& Martin, M. (2011). Social capital, health and life satisfaction in 50 countries. Health and Place, 17, 1044-1053. https://doi.org/10.1016/j.healthplace.2011.06.010

Gray, J. A. (1982). The neuropsychology of anxiety: An inquiry into the functions of the septohippocampal system. Oxford, England: Clarendon Press.

Horwitz, A. V. (2013). Anxiety: A short history. John Hopkins University Press.

Jonas, E., McGregor, I., Klackl, J., Agroskin, D., Fritsche, I., Holbrook, C., Nash, K. Proulx, T., \& Quirin, M. (2014). Threat and defense: from anxiety to approach. In J. M. Olson, M. P. Zanna (Eds.), Advances in Experimental Social Psychology (pp. 219-286). Academic Press.

Kessler, T., Mummendey, A., Funke, F., Brown, R., Binder, J., Zagefka, H., ... \& Maquil, A. (2010). We all live in Germany but... Ingroup projection, group-based emotions and prejudice against immigrants. European Journal of Social Psychology, 40, 985-997.

Marshall, H., Tooher, R., Collins, J., Mensah, F., Braunack-Mayer, A., Street, J., \& Ryan, P. (2012). Awareness, anxiety, compliance: community perceptions and response to the threat and reality of an influenza pandemic. American journal of infection control 40, 270-272. https://doi.org/10.1016/j.ajic.2011.03.015 
Marteau, T. M., \& Bekker, H. (1992). The development of a six-item short-form of the state scale of the Spielberger State-Trait Anxiety Inventory (STAI). British Journal of Clinical Psychology 31, 301-306. https://doi.org/10.1111/j.2044-8260.1992.tb00997.x

Pettigrew, T. F., \& Meertens, R. W. (1995). Subtle and blatant prejudice in Western Europe. European Journal of Social Psychology 25, 57-75. https://doi.org/10.1002/ejsp.2420250106

Putnam, R. D. (1995). Bowling alone: America's declining social capital. Journal of Democracy, 6, 65. https://doi.org/10.1353/jod.1995.0002

Rachman, S. (1977). The conditioning theory of fear acquisition: a critical examination. Behaviour Research and Therapy, 15, 375-387. https://doi.org/10.1016/00057967(77)90041-9

Rank, O. (1909/1914). Myth of the Birth of the Hero: A Psychological Interpretation of Mythology. Nervous \& Mental Disease Monograph Series, 18.

Sartre, J. (1956). Being and Nothingness. Philosophical Library.

Schaller, M., \& Neuberg, S. L. (2012). Danger, Disease, and the Nature of Prejudice(s). In J. M. Olson, M. P. Zanna (Eds.), Advances in Experimental Social Psychology (pp. 1-54). Academic Press.

Schoemann, A. M., Boulton, A. J., \& Short, S. D. (2017). Determining power and sample size for simple and complex mediation models. Social Psychological and Personality Science, 8, 379-386.

Scott, S., \& Duncan C. J. (2001). Biology of Plagues Evidence from Historical Populations. Cambridge University Press.

Stephan, W. G., \& Stephan, C. W. (2000). An integrated threat theory of prejudice. In S. Oskamp 
(Ed.), Reduce prejudice and discrimination (pp. 23-46). Mahwah, NJ: Lawrence Erlbaum Associates.

Thompson, R. R., Garfin, D. R., Holman, E. A., \& Silver, R. C. (2017). Distress, worry, and functioning following a global health crisis: A national study of American's responses to Ebola. Clinical psychological Science, 5, 513-521.

Wheaton, M. G., Abramowitz, J. S., Berman, N. C., Fabricant, L. E., \& Olatunji, B. O. (2012). Psychological Predictors of Anxiety in Response to the H1N1 (Swine Flu) Pandemic. Cognitive Therapy and Research 36, 210-218. https://doi.org/10.1007/s10608-011-93533

Wohl, M. J. A., \& Branscombe, N. R. (2009). Group threat, collective angst, and ingroup forgiveness for the war in Iraq. Political Psychology 30, 193-217. https://doi.org/10.1111/j.1467-9221.2008.00688.x

Wohl, M. J. A., Squires E. C., \& Caouette, J. (2012). We were, we are, will we be? the social psychology of collective angst. Social and Personality Psychology Compass 6), 379-391. https://doi.org/10.1111/j.1751-9004.2012.00437.x

Worldometer. (2020, April 14. COVID-19 coronavirus pandemic. https://www.worldometers.info/coronavirus/

Witte, K., \& Allen, M. (2000). A meta-analysis of fear appeals: Implications for effective public health campaigns. Health Education \& Behavior, 27, 591-615. https://doi.org/ $10.1177 / 109019810002700506$

Ungaretti, J., Etchezahar, E., \& Barreiro, A. (2018). Validation of the subtle and blatant prejudice scale towards indigenous people in Argentina. Current Psychology. doi:10.1007/s12144-018-9844-4 